\title{
DESCRIÇÃO DOS PROCEDIMENTOS PARA IMPLANTE DE ENXERTO HEPÁTICO ORTOTÓPICO TOTAL EM SUÍNOS
}

\author{
Total liver graft implantation procedures in orthotopic pig transplantation
}

\author{
Marcus Vinicius Henriques Brito; Luane Cristine Batista Cunha; Erick Kiichi Miyagawa; Alessandro Augusto Viana Oliveira e \\ Sousa; Luís Paulo de Miranda Araújo Soares; Nathalya Botelho Brito
}

\begin{abstract}
RESUMO
Objetivo: Descrever os procedimentos de hepatectomia total no receptor e de implante de enxerto hepático total em transplante ortotópico em suínos. Métodos: Foram utilizados 14 porcos Sus escrofa domesticus fêmeas, pesando entre 5 e $8 \mathrm{~kg}$, os quais foram distribuídos em dois grupos: doadores e receptores, sendo considerados somente os últimos no resultado da presente pesquisa. Para iniciar o ato operatório, os animais foram previamente anestesiados e colocados em monitorização transoperatória, sendo em seguida submetidos aos procedimentos necessários para a hepatectomia do receptor e implante do enxerto total. Resultados: A cirurgia no animal receptor teve duração total média de 142,6 minutos, enquanto a fase anepática durou em média 64,6 minutos. Conclusão: As técnicas de hepatectomia em animal receptor e implante de enxerto total descritas são viáveis, eficazes e reprodutíveis, possibilitando o treinamento de profissionais e acadêmicos, bem como o desenvolvimento de futuras pesquisas envolvendo o transplante hepático.
\end{abstract}

Descritores: Fígado, Transplante, Suínos

Instituição:

Laboratório de Cirurgia Experimental da Universidade do Estado do Pará, Belém, PA.

\section{Correspondência:}

Marcus Vinicius Henriques Brito

Rua dos Pariquis 1283, Apto.604, CEP 66033-590, Belém-PA, Brasil.

Tel: (91) 3242-6636

e-mail: marcusbrito@amazon.com.br

\section{INTRODUÇÃO}

Desde os primeiros transplantes hepáticos clínicos realizados em 1963 nos Estados Unidos e em 1968 no Brasil, essa modalidade terapêutica tem sido utilizada de forma eficiente para uma variedade de doenças hepáticas agudas e crônicas em estágio terminal, para as quais nenhuma outra terapia satisfatória está disponível. ${ }^{1}$

No entanto, o transplante hepático continua sendo um procedimento arriscado e devem ser consideradas a alta morbidade e mortalidade devida à rejeição, aos problemas biliares e à disfunção primária, quando é indicado esse tipo de transplante. ${ }^{2}$

Os resultados obtidos com transplantes hepáticos dependem da superação das dificuldades técnicas, da melhoria do atendimento clínico, melhor seleção dos pacientes, descoberta de novas drogas imunossupressoras e experiência adquirida pelo grupo transplantador. ${ }^{3}$

Para superar as dificuldades técnicas é imprescindível que médicos e acadêmicos realizem atividade prática em modelo animal, visto que as habilidades psicomotoras e a habilitação para o ato cirúrgico não se consolidam apenas no exercício teórico. ${ }^{4}$ 
A escassez de trabalhos descrevendo a técnica de transplante hepático em suínos justifica a realização desta pesquisa, que objetiva descrever os procedimentos de hepatectomia do receptor e de implante de enxerto no transplante ortotópico em suínos, a fim de colaborar com o treinamento e aperfeiçoamento da técnica, diminuindo assim a incidência de complicações operatórias.

\section{MÉTODO}

A presente pesquisa foi aprovada pelo Comitê de Ética e Pesquisa do Centro de Ciências Biológicas e da Saúde da Universidade do Estado do Pará (Protocolo $\mathrm{N}^{\circ} 2 / 2009$ ), sendo realizada no Laboratório de Cirurgia Experimental da Universidade do Estado do Pará. Seguiram-se as normas do Colégio Brasileiro de Experimentação Animal (COBEA) e legislação nacional para vivissecção animal em vigor (Lei federal 11.794 de 08 de outubro de 2008).

\section{Amostra}

Foram utilizados 14 porcos fêmeas Sus escrofa domesticus, pesando entre 5 e $8 \mathrm{~kg}$, os quais foram distribuídos em dois grupos: doadores e receptores, sendo considerados somente os últimos (sete receptores) para a presente pesquisa. Os animais ficaram alojados em Biotério apropriado com água ad libitum, oferta de $500 \mathrm{~g}$ de ração diariamente, temperatura ambiente e iluminação natural. Houve jejum pré-operatório de 24 h.

\section{Anestesia e monitorização dos animais}

A indução anestésica foi feita com cetamina $10 \mathrm{mg} / \mathrm{kg}$, associada à xilazina $20 \mathrm{mg} / \mathrm{kg}$ em uma proporção de 2:1 por via intramuscular na região glútea do porco na mesma seringa para porcos com $5 \mathrm{~kg}$, ainda no biotério. Após sedação, foram submetidos aos procedimentos de limpeza, levados à sala operatória, intubados e conectados a respirador orotraqueal. Foram realizadas monitoração cardíaca, monitoração da pressão arterial média (PAM) e oximetria.

A intubação foi realizada com auxílio de um laringoscópio com lâmina reta de $25 \mathrm{~cm}$, sonda orotraqueal, $\mathrm{n}^{\mathrm{o}}$ 4,5 sem cuff, conectada ao sistema de ventilação controlada com respirador Takaoka modelo 600, mantendo-se freqüência respiratória entre 15 e 20 ipm. A manutenção anestésica foi realizada com halotano e com fentanil 3-5 $\mu \mathrm{g} / \mathrm{kg}$.

Realizou-se então a anti-sepsia da região cervical até a região pélvica.

Na região cervical foi realizada cateterização da veia jugular interna esquerda para a infusão de $45 \mathrm{gts} / \mathrm{min}$ de soro fisiológico contínuo, bem como da artéria carótida esquerda para a verificação da PAM.

\section{Procedimento Operatório}

A técnica de transplante hepático em suínos descrita por Brito e col. ${ }^{5,6}$ é dividida em quatro partes: captação do fígado no animal doador, backtable, hepatectomia do animal receptor e implante do enxerto total. No presente estudo são abordados somente os dois últimos procedimentos.

\section{Hepatectomia do animal receptor}

Inicia-se a hepatectomia com a laparotomia longitudinal mediana supra-umbilical. Realiza-se a dissecção vascular sendo que, no receptor, esta deve ser realizada o mais próximo possível ao parênquima hepático, deixando no animal os cotos vasculares longos ao ser extraído o fígado.

Faz-se a dissecção da veia cava infra hepática, dissecção e ligaduras dos ramos colaterais da veia porta, artéria hepática e ligadura e secção do ducto colédoco. Segue-se então uma falsa ligadura nas veias frênicas, (Figura 1) ficando estas frouxas nesse momento. Os ligamentos hepáticos são então seccionados, ficando o fígado preso somente pelos vasos.

Figura 01 - Clampeamento das veias cava e porta e artéria hepática e confecção das falsas ligaduras das veias frênicas, para a exérese do fígado no animal receptor.

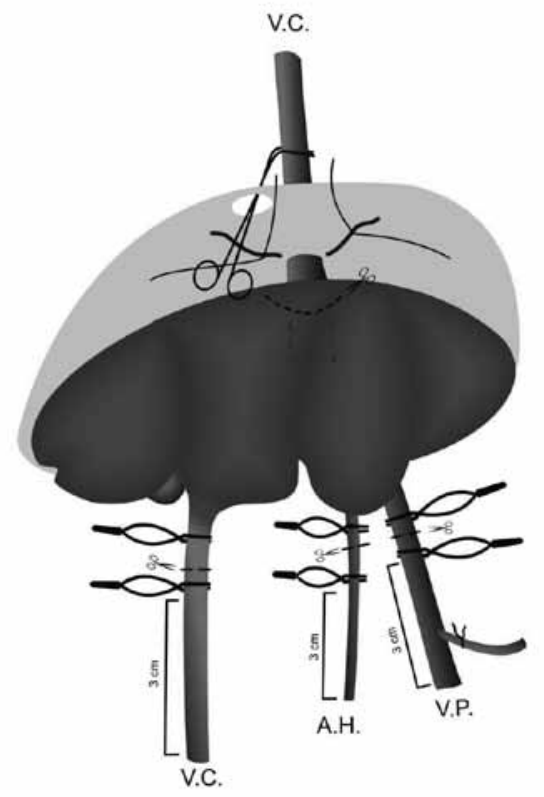

São infundidos $10 \mathrm{ml} / \mathrm{kg}$ de bicarbonato de sódio $8,4 \%$ venoso pelo anestesista após o clampeamento das veias cava, infra hepática e porta, assim como a artéria hepática comum com clamps Bulldogs, o mais próximo possível do parênquima hepático. Realiza-se a abertura do diafragma para o posterior pinçamento da veia cava supra hepática com auxílio de uma pinça Satinsky de $2,5 \mathrm{~cm}$ de boca.

Tracionam-se as falsas ligaduras das veias frênicas e clampeia-se a veia cava supra hepática dentro do tórax, seccionando a mesma em localização abdominal, em sua emergência do parênquima hepático.

Os demais vasos entre os clamps Bulldogs, a veia cava infra hepática, veia porta e artéria hepática são seccionados. Remove-se então o fígado do receptor.

\section{Implante do enxerto}

Primeiramente é feito o preparo da boca da veia cava supra hepática, ressecados fragmentos residuais de fígado. Obtém-se uma boca circular da veia cava supra no diafragma e uma abertura 
lateral. É então realizada a sutura da abertura lateral, adequando o tamanho da "boca" da cava do receptor ao da cava do enxerto (Figura 2). Posteriormente, as anastomoses são iniciadas pela veia cava supra hepática, seguida da veia porta, cava infra hepática e artéria hepática.

Figura 02 - Vista abdominal do preparo da "boca" anastomótica da veia cava supra hepática do receptor (sutura diafragmática)

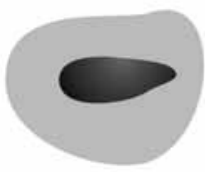

$\mathrm{N}^{\circ} 1$

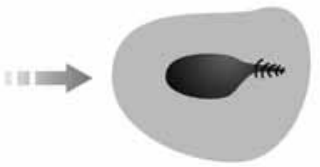

$\mathrm{N}^{\circ} 2$

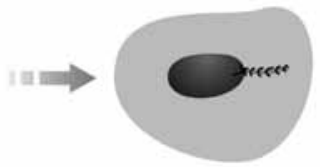

$N^{\circ} 3$

\section{Sequência das anastomoses}

O enxerto é posicionado no espaço subdiafragmático direito e a anastomose da veia cava supra hepática é realizada. Esse procedimento inicia-se no backtable, com a passagem do fio de polipropileno 6-0 biagulhado: as duas agulhas são passadas de fora para dentro na veia cava do enxerto e, em seguida, de dentro para fora, na borda posterior da boca da cava do animal receptor. O nó é confeccionado e as agulhas são posicionadas para lados opostos da anastomose. Com outro fio de polipropileno 6-0 monoagulhado faz-se um ponto simples de reparo na borda anterior da anastomose. É então posicionada uma sonda de nelaton $n^{\circ} 8$ dentro do vaso e confeccionado o chuleio por ambos os lados da anastomose (Figura 3).

Figura 03 - Esquema da anastomose da veia cava supra hepática do animal receptor

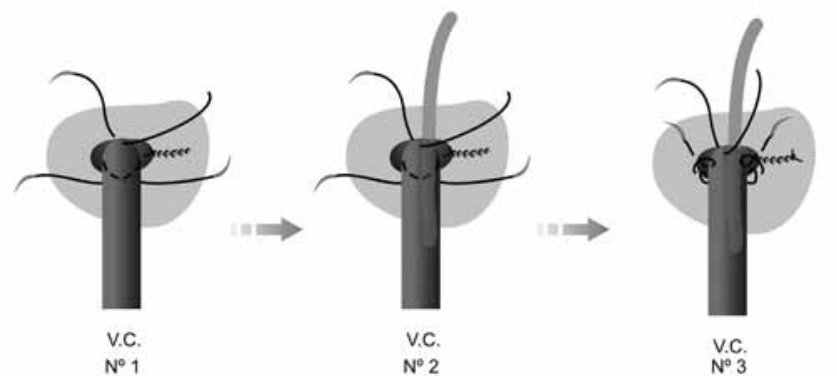

É então realizada a anastomose portal. Finalizadas as duas anastomoses é infundido $10 \mathrm{ml} / \mathrm{kg}$ de bicarbonato de sódio $8,4 \%$ venoso, sendo abertos o Satinsky da veia cava supra hepática e o Bulldog da veia porta por 10 segundos a cada minuto durante os cinco primeiros minutos da reperfusão (Pós condicionamento hepático).

Após cinco minutos, é liberado definitivamente o fluxo portal havendo perfusão sanguínea definitiva do enxerto, o que finaliza a fase de isquemia (anepática).

Já com fluxo hepático portal presente, realiza-se anastomose da veia cava infra hepática e da artéria hepática do mesmo modo que a anastomose anterior. A sutura do diafragma é feita ao final da cirurgia com fio vicryl 3-0. Por fim, realiza-se colecistojejunostomia com vicryl 3-0.

Passados 30 minutos após os procedimentos, realiza-se a eutanásia com injeção de $50 \mathrm{ml}$ de Kcl 10\% EV. A carcaça dos animais é descartada em lixo biológico envolvida em saco plástico hospitalar, segundo a legislação em vigor.

\section{RESULTADOS}

A cirurgia no animal receptor teve duração total média de 142,6 minutos, enquanto a fase anepática durou em média 64,6 minutos. (Tabela 1)

Dentre as etapas da cirurgia no animal receptor, os tempos médios dos procedimentos foram: dissecção da veia cava infra hepática em 2,7'; dissecção da veia porta em 8,8 '; dissecção colédoco em 1,5'; dissecção da artéria hepática em 8,5'; secção dos ligamentos hepáticos em 4,2'; dissecção da veia cava supra hepática em 2,7'; “clampeamento" da veia cava, veia porta e artéria hepática em 0,5 '; preparo das "bocas” anastomóticas em 11,2' (Tabela 2)

A confecção das anastomoses vasculares das veias supra hepática e porta demorou em média 27,6' e 15,6', respectivamente. (Tabela 3)

Tabela 1 - Tempos das etapas operatórias dos transplantes hepáticos em porcos realizados no LCE-CCBS-UEPA 2009.

\begin{tabular}{|c|c|c|}
\cline { 2 - 3 } \multicolumn{1}{c|}{} & \multicolumn{2}{|c|}{ Etapas (tempo) } \\
\hline \multirow{2}{*}{ Transplante } & Fase anepática & $\begin{array}{c}\text { Tempo total } \\
\text { cirurgia no } \\
\text { receptor }\end{array}$ \\
\hline 1 & $69^{\prime}$ & $183^{\prime}$ \\
\hline 2 & $66^{\prime}$ & $121^{\prime}$ \\
\hline 3 & \multicolumn{2}{|c|}{ Óbito } \\
\hline 4 & $60^{\prime}$ & $126^{\prime}$ \\
\hline 5 & $68^{\prime}$ & $112^{\prime}$ \\
\hline 6 & $60^{\prime}$ & $117^{\prime}$ \\
\hline 7 & $646^{\prime}$ & $142,6^{\prime}$ \\
\hline Média & \multicolumn{2}{|c|}{} \\
\hline
\end{tabular}

LCE-CCBS-UEPA: Laboratório de Cirurgia Experimental do Centro de Ciências Biológicas da Universidade do Estado do Pará. 
Tabela 2 - Tempos das etapas operatórias dos transplantes hepáticos em porcos realizados no LCE-CCBS-UEPA 2009

\begin{tabular}{|c|c|c|c|c|c|c|c|c|}
\hline \multirow[b]{2}{*}{ Transplante } & \multicolumn{8}{|c|}{ Etapas Receptor (tempo) } \\
\hline & $\begin{array}{l}\text { Dis. } \\
\text { VCIH }\end{array}$ & $\begin{array}{l}\text { Dis. } \\
\text { VP }\end{array}$ & $\begin{array}{l}\text { Dis. } \\
\text { Col. }\end{array}$ & $\begin{array}{l}\text { Dis. a } \\
\text { Hep. }\end{array}$ & $\mid \begin{array}{c}\text { Sec. } \\
\text { dos } \\
\text { Ligam. }\end{array}$ & \begin{tabular}{|l} 
Dis. \\
VC \\
Sup.
\end{tabular} & $\begin{array}{l}\text { Clamp. } \\
\text { VC / VP/ } \\
\text { a Hep. / } \\
\text { VC Sup. }\end{array}$ & $\begin{array}{l}\text { Prep. } \\
\text { Bocas } \\
\text { Anast. }\end{array}$ \\
\hline 1 & $3^{\prime}$ & $5^{\prime}$ & $<1^{\prime}$ & $4^{\prime}$ & $10^{\prime}$ & $4^{\prime}$ & $1^{\prime}$ & $12^{\prime}$ \\
\hline 2 & $4^{\prime}$ & $5^{\prime}$ & $2^{\prime}$ & $9^{\prime}$ & $4^{\prime}$ & $4^{\prime}$ & $1^{\prime}$ & $12^{\prime}$ \\
\hline 3 & $3^{\prime}$ & $13^{\prime}$ & $2^{\prime}$ & $7^{\prime}$ & $4^{\prime}$ & $2^{\prime}$ & $1^{\prime}$ & $14^{\prime}$ \\
\hline 4 & $1^{\prime}$ & $5^{\prime}$ & $2^{\prime}$ & $9^{\prime}$ & $4^{\prime}$ & $5^{\prime}$ & $<1^{\prime}$ & $10^{\prime}$ \\
\hline 5 & $1^{\prime}$ & $8^{\prime}$ & $2^{\prime}$ & $9^{\prime}$ & $2^{\prime}$ & $2^{\prime}$ & $<1^{\prime}$ & $10^{\prime}$ \\
\hline 6 & $3^{\prime}$ & $3^{\prime}$ & $1^{\prime}$ & $6^{\prime}$ & $1^{\prime}$ & $1^{\prime}$ & $1^{\prime}$ & $9^{\prime}$ \\
\hline 7 & $4^{\prime}$ & $23^{\prime}$ & $2^{\prime}$ & $16^{\prime}$ & $5^{\prime}$ & $1^{\prime}$ & $<1^{\prime}$ & $12^{\prime}$ \\
\hline Média & $2,7^{\prime}$ & $8,8^{\prime}$ & $1,5^{\prime}$ & $8,5^{\prime}$ & $4,2^{\prime}$ & $2,7^{\prime}$ & $0,5^{\prime}$ & $11,2^{\prime}$ \\
\hline
\end{tabular}

LCE-CCBS-UEPA: Laboratório de Cirurgia Experimental do Centro de Ciências Biológicas da Universidade do Estado do Pará.

Dis. VCIH: Dissecção veia cava infra hepática.

Dis. VP: Dissecção veia porta.

Dis. Col: Dissecção colédoco.

Dis. a Hep.: Dissecção artéria hepática.

Sec. Lig. Hep.: Secção ligamentos hepáticos.

Dis. vc Sup.: Dissecção da veia cava supra hepática.

Clamp. VC / VP/ a Hep.: "Clampeamento" da veia cava, veia porta e artéria hepática.

Prep. Bocas Anast.: Preparo das "bocas" anastomóticas

Tabela 3 - Tempos das etapas operatórias dos transplantes hepáticos em porcos realizados no LCE-CCBS-UEPA 2009.

\begin{tabular}{|c|c|c|}
\cline { 2 - 3 } \multicolumn{1}{c|}{} & \multicolumn{2}{c|}{ Anastomose (tempo) } \\
\hline Transplante & VCSH & VP \\
\hline 1 & $32^{\prime}$ & $10^{\prime}$ \\
\hline 2 & $25^{\prime}$ & $23^{\prime}$ \\
\hline 3 & \multicolumn{2}{|c|}{ óbito } \\
\hline 4 & $21^{\prime}$ & \multicolumn{2}{c|}{ óbito } \\
\hline 5 & $36^{\prime}$ & $18^{\prime}$ \\
\hline 6 & $24^{\prime}$ & 15 \\
\hline 7 & $27,6^{\prime}$ & $12^{\prime}$ \\
\hline Média & & $15,6^{\prime}$ \\
\hline
\end{tabular}

LCE-CCBS-UEPA: Laboratório de Cirurgia Experimental do Centro de Ciências Biológicas da Universidade do Estado do Pará.

VCSH: Veia cava supra hepática.

VP: Veia porta.

\section{DISCUSSÃO}

O desenvolvimento do transplante de fígado tem representado um enorme desafio na prática clínico-cirúrgica, não apenas pela complexidade da técnica, como também pela escassez de órgãos disponíveis. $^{7}$

Mais recentemente, com o aumento das taxas de sobrevivência dos pacientes, a recorrência da doença de base que indicou o transplante, as complicações tardias da imunossupressão e a manutenção de boa qualidade de vida tornaram-se novos desafios. ${ }^{7}$

Em função da complexidade técnica envolvida no transplante hepático, o treinamento das equipes anestésico-cirúrgicas através de cirurgias experimentais em animais tem sido considerado passo fundamental antes de sua aplicação clínica. ${ }^{8}$

No presente estudo, os animais apresentavam massa corporal entre 5 e $8 \mathrm{Kg}$ o que, apesar de dificultar a técnica em comparação ao uso de animais de maior porte devido o menor calibre dos vasos nos animais utilizados, proporcionou maior destreza no treinamento e economia com drogas e anestésicos durante o procedimento.

O preparo dos procedimentos iniciou-se na véspera, com a verificação do tamanho e peso dos animais destinados ao procedimento para calcular as doses das drogas a serem administradas, avaliar seu estado de saúde e iniciar o jejum, a fim de evitar complicações como broncoaspiração ou dificuldades operatórias devido à plenitude gástrica, e escolher quem seria o animal doador e o receptor. Isso é importante, pois o animal receptor deve ser maior que o doador para que um fígado relativamente pequeno seja implantado em cavidade um pouco maior que seu tamanho, facilitando a confecção das anastomoses vasculares.

A cirurgia no receptor teve duração média de 142,6 minutos e a fase anepática teve média de 64,6 minutos, tendo tempos correspondentes semelhantes aos apresentados no trabalho de Torres e col. ${ }^{1}$ que foram de 140,58 e 69 minutos respectivamente. A cirurgia de retirada do enxerto foi realizada em tempo e de forma satisfatória com ocorrência de poucas complicações, assim como o backtable, que teve duração média de 33 minutos. ${ }^{6}$ Esse tempo representou uma redução de 23,6 minutos em relação à técnica de Torres e col., ${ }^{1}$ revelando que foram realizados em tempo hábil tanto a perfusão e o preparo do órgão quanto os pontos de ancoragem na extremidade posterior da veia cava supra hepática do enxerto que vieram a facilitar sobremaneira a anastomose no receptor.

Assim como no animal doador, na cirurgia do animal receptor também se observou um decréscimo gradual na maioria dos tempos operatórios. Em relação à dissecção dos vasos, a da veia porta foi o procedimento mais demorado, durando em média 8,8 minutos (Tabela 3), devido ao grande número de ramos que devem ser cuidadosamente dissecados e ligados durante esse procedimento.

A anastomose da veia cava supra hepática foi o procedimento mais demorado e trabalhoso de todo o transplante, mantendo média de 27,6 minutos, devido ao seu curto trajeto abdominal, que obriga sua ressecção juntamente com segmento de parênquima hepático, que será dissecado liberando a "boca" anastomótica vascular e o restrito espaço que resta ao ser posicionado o enxerto para a anastomose. Para diminuir as perdas sanguíneas e facilitar esse procedimento, realizou-se ligadura falsa nas veias frênicas (Figura 1) antes da retirada do fígado do receptor. Esses vasos desembocam diretamente na veia cava supra hepática e dificultam a anastomose devido ao seu sangramento constante. Essas ligaduras falsas foram soltas ao final da anastomose.

Apesar do tempo necessário para realização da anastomose da veia 
cava supra hepática ter sido relativamente longo quando comparado aos resultados obtidos por Torres e col., ${ }^{1}$ não representou prejuízo ao procedimento; já o tempo necessário à realização da anastomose da veia cava infra hepática foi bastante satisfatório, em torno de 15,6 minutos.

Não foram citados os tempos de realização da anastomose da artéria hepática, veia cava inferior e colecistojejunostomose, pois as mesmas não foram realizadas nos presentes transplantes, visto que nesta fase do trabalho, objetivou-se avaliar a viabilidade inicial do enxerto.

A instabilidade hemodinâmica é o aspecto mais marcante do procedimento, visto que porcos são muito sensíveis a perdas sanguíneas. ${ }^{9}$ Segundo Leite, Benitez e Amaral, ${ }^{10}$ os principais fatores responsáveis pela instabilidade na fase anepática são a rápida perda sanguínea gerada pela manipulação cirúrgica e reposição inadequada de fluídos. Tais fatores sempre alteram a pré-carga do coração.

Já na fase anepática, além dos fatores anteriormente mencionados, soma-se a oclusão da veia cava inferior que acarreta queda do retorno venoso dos membros inferiores e território esplâncnico em torno de $50 \%$, o que leva ao acúmulo de metabólitos ácidos no leito congesto. Posteriormente, estes metabólitos intensificam o quadro hipotensivo. ${ }^{10}$

Nos transplantes de número 1 a 4, utilizou-se transfusão sanguínea para reposição volêmica, ocorrendo dois óbitos intra operatórios de receptores, nos transplantes $n^{\circ} 3$ e $n^{\circ} 4$. Devido a esse elevado índice de mortalidade, nos transplantes de $n^{\circ} 5$ a 7 utilizou-se Ringer Lactato e solução hipertônica de cloreto de sódio a 7,5\% para manutenção, não tendo ocorrido óbito, o que indica a possibilidade de reação hemolítica transfusional aguda, mesmo tendo-se utilizado animais da mesma ninhada, já que nos suínos, 16 sistemas de grupos sangüíneos são reconhecidos internacionalmente (A, B, C, D, E, F, G, H, I, J, K, L, M, N, O, P). ${ }^{11}$

Após o implante do enxerto, pode ocorrer síndrome pósreperfusão, que constitui o mais alto grau de instabilidade hemodinâmica e é caracterizada por bradiarritmia, diminuição da PAM e redução da resistência vascular periférica. ${ }^{12}$ Essa síndrome resultou nos óbitos ocorridos após o desclampeamento das ligaduras e reperfusão do enxerto.

Qualquer fígado transplantado apresenta alguma extensão de disfunção, já que a lesão de isquemia-reperfusão é fenômeno inevitável a todo órgão transplantado. ${ }^{13}$ A reperfusão após período de isquemia resulta em dois efeitos principais: perda da viabilidade do endotélio dos sinusóides e a ativação das células de Kupffer e neutrófilos. ${ }^{13}$ Várias estratégias tem sido descritas para prevenir a injuria de isquemia e reperfusão em transplantes de órgãos sólidos. Dentre elas, tem-se a utilização de tampões que funcionam como a primeira linha de defesa do organismo contra variações na concentração de íons hidrogênio, sendo o bicarbonato o tampão mais importante no meio extracelular. ${ }^{14}$

Outra forma de preservação de órgãos é a utilização de substâncias de conservação que têm como objetivo manter os órgãos em condições adequadas durante o período de remoção do doador até o implante no receptor $^{15}$, sendo a solução da Universidade de Wisconsin (UW) considerada a melhor para preservação hepática. ${ }^{15,16}$

Entretanto, novos estudos estão sendo constantemente desenvolvidos através da análise da eficácia de novas substâncias ${ }^{15-17}$ ou pequenas modificações da solução UW. ${ }^{18-20}$

Como desafio para a melhoria do modelo de transplante hepático em suínos, tem-se o desenvolvimento de novas soluções de preservação de baixo custo, além da realização de circulação extracorpórea por meio de bomba artesanal em desenvolvimento no Laboratório de Cirurgia Experimental da Universidade do Estado do Pará.

\section{CONCLUSÃO}

As técnicas de hepatectomia em animal receptor e implante de enxerto total descritas são viáveis, eficazes e reprodutíveis, possibilitando o treinamento de profissionais e acadêmicos, bem como o desenvolvimento de futuras pesquisas envolvendo o transplante hepático.

\section{ABSTRACT}

Purposes: To report procedures in receptor animal of hepatectomy and total liver graft implantation in pig orthotopic transplantation. Methods: Fourteen female pigs Sus escrofa domesticus were utilized, weighing between 5 and $8 \mathrm{~kg}$, which were distributed in 2 groups: donors and receptors, being only the last ones considered in the result of this research. In order to initiate the surgery, animals were previously anesthetized and placed under transoperative monitoring, being immediately submitted to the necessary procedures for the hepatectomy of the receptor and total graft implantation. Results: The mean times of anhepatic stages and receptor surgery were 64.6 and 142.6 minutes. Conclusion: The reported techniques of hepatectomy in the receptor animal and total implantation of the graft are feasible, effective and reproducible, enabling the training of professionals and medical students, as well as the development of further researches involving liver transplantation.

Keywords: Liver, Transplantation, Swine

\section{REFERÊNCIAS}

1. Torres OJM, Barbosa ES, Baros NDC, Pantoja PB, Servin ETN, Moreira PCO, et al. Transplante hepático ortotópico experimental em suínos: resultados iniciais. $\mathrm{J}$ Bras Transpl. 2005;8(2):305-8.

2. Sette HJ, Bachella T, Cerqueira M, Machado C. Análise crítica da política de alocação de órgãos para transplante de fígado no Brasil. Rev. Hosp. Clin. 2003;58(3):179-84

3. Marroni CA, Brandão ABM, Zanotelli ML, Cantisani GPC. Transplante Hepático em Adultos. Revista AMRIGS. 2003;47(1), p. 29-37.

4. Schanaider A, Silva PC. Uso de animais em cirurgia experimental. Acta Cir Bras 
[serial online] 2004 Jul-Ag;19(4). Disponível em URL: http://www.scielo.br/acb [também em CD-ROM]

5. Brito MVH, Soares LPMA, Cunha LCB, Braga TGM, Ferreira BP, Vera MV. Proposta de modificação técnica da captação hepática no transplante ortotópico em suínos. Transplantation Proceedings. No prelo.

6. Brito MVH, Cunha LCB, Miyagawa EK, Ferreira BP, Rodrigues JB, Sabbá MF. Descrição dos procedimentos de "backtable" no transplante hepático ortotópico em suínos. Transplantation Proceedings. No prelo.

7. Ferraz BH, Afonso RC. Evolução e perspectivas do transplante de fígado no Brasil Rev.Prat.Hosp. 2007;50(9):167-70.

8. Torres OJM, Pantoja PB, Barbosa ES, Barros CA, Servin ETN, Servin ETN Hemodynamics alterations during orthotopic liver experimental transplantation in pigs. Acta Cir Bras. 2008;23(2):135-9.

9. Torres OJM, Pantoja PB, Barbosa ES, Viegas RA Servin ETN, Moreira PCO, e col. Transplante hepático ortotópico expermental em suínos : aspectos. J Bras Transpl. 2005;8(2):309-13.

10. Leite JAA, Benitez PRBB, Amaral RVG. 1mplicações Anestésicas do Transplante Hepático-Estudo em Suínos. Rev Bras Anest. 1991;41(4):253-56.

11. Feldman BF, Zink1 JG, Jain NC. Schalm's Veterinary Hematology. 5 ed. Philadelphia: Lippincott Williams \& Wilkins, 2000:1344.

12. Aggarwal S, Kang Y, Freeman JA. et al. Postperfusion syndrome: cardiovascular collapse following hepatic reperfusion during liver transplantation. Transplant Proc. 1987;4(3):54-5.
13. Miranda LEC, Viaro F, Ceneviva R, Evora PRB. Bases experimentais da lesão por isquemia e reperfusão do fígado: revisão. Acta cir bras. 2004;19(1):3-12

14. Yamashita AM, Takaoka F, Auler JOC, Iwata NM. . Anestesiologia-SAESP. $5^{\circ}$ ed. São Paulo: Atheneu; 2001.

15. Feng L, Zhao N, Yao X, Sun X, Du L; Diao X, et al. Histidine-tryptophanketoglutarate solution vs. university of wisconsin solution for liver transplantation : A systematic review. Liver transplantation. 2007;13(8):1125-36.

16. Spiegel HU, Schleimer K, Kranz D, Oldhafer KJ. Organ Preservation with EC, HTK, and UW Solutions in Orthotopic Liver Transplantation in Syngeneic Rats. Part I: Functional Parameters. Journal of Investigative Surgery. 1998;11(1):49-56.

17. Song S. Comparison of the protective effects of phosphate-buffered sucrose and University of Wisconsin solution in a non-heart-beating liver donor experiment Transplant Proc. 2001;33(1):884-5.

18. Gou RF, Mosbah IB, Serafin A, Abdennebi HB, Roselló-Catafau J, Peralta C. New preservation strategies for preventing liver grafts against cold ischemia reperfusion injury. Journal of Gastroenterology and Hepatology. 2006;22(7): 1120-6.

19. Gu XP, Xu FT, Jiang Y, Qiu YD, Ding YT. Pyrrolidine Dithiocarbamate Added to University of Wisconsin Solution Inhibits Reperfusion Injury after Orthotopic Liver Transplantation in Rats Annals of Clinical \& Laboratory Science. 2004;34:187-94.

20. Mosbah IB, Massip-Salcedo M, Fernandez-Monteiro I, Xaus C, Bartrons R, Boillot $\mathrm{O}$ et al. Addition of Adenosine Monophosphate-Activated Protein Kinase Activators to University of Wisconsin Solution: A Way of Protecting Rat Steatotic Livers. Liver Transpl. 2007;13:410-25. 